\title{
A PROPÓSITO DE \\ MEDIA HORA JUGANDO A LOS DADOS
}

\author{
Isidro Hernández Gutiérrez \\ Tenerife Espacio de las Artes (TEA)
}

\section{RESUMEN}

Media hora jugando a los dados fue escrito por Agustín Espinosa como contribución a la vida, signo y obra del pintor José Jorge Oramas (Las Palmas de Gran Canaria, 1911-1935), de la Escuela Luján Pérez. Se trata de uno de los textos vanguardistas en lengua española por excelencia, en el que se celebra el alcance y trascendencia de la obra del pintor grancanario. PALABRAS ClAVE: vanguardia, pintura, poesía, nueva figuración, arte.

ON MEDIA HORA JUGANDO A LOS DADOS

\section{Abstract}

Media hora jugando a los dados was written by Agustín Espinosa as a contribution to the life, sign and work of the painter José Jorge Oramas (Las Palmas de Gran Canaria, 1911-1935), from the Luján Pérez School. It is one of the avant-garde texts in the Spanish language par excellence, in which the scope and significance of the work of the painter from Gran Canaria is celebrated.

KEYwORDS: avant-garde, painting, poetry, new figuration, art.

DOI: https://doi.org/10.25145/j.refiull.2021.42.06

Revista de Filología, 42; enero 2021, pp. 79-93; ISSN: e-2530-8548 
Media hora jugando a los dados se sitúa en un lugar de excepción dentro del marco de la trayectoria de la vanguardia canaria. Agustín Espinosa escoge este lema de signo lúdico para su conferencia dictada en el Círculo Mercantil de Las Palmas de Gran Canaria el día 20 de abril de 1933, como contribución a la vida, signo y obra del pintor José Jorge Oramas (Las Palmas de Gran Canaria, 1911-1935). El texto se nutre, en verdad, de un artículo más breve escrito a manera de presentación del pintor, y publicado por Espinosa en el Diario de Las Palmas el 13 de abril de 1933 bajo el lema "La trágica orfandad de J. Jorge Oramas», dentro del epígrafe Mártires del insularismo. Se trata de un texto crucial en el contexto de la aventura de la generación de vanguardia, escrito por el que, acaso, sea el autor más relevante de aquella irrepetible pléyade. No es solo una presentación o recensión crítica de la obra del pintor grancanario. Muy al contrario, nos encontramos ante un texto de celebración de uno de los protagonistas de aquella hora, y ejemplifica a la perfección el sentimiento o la voluntad de afirmación generacional -joven y entusiastade la que participan los vanguardistas canarios. En efecto, la escritura del autor de Media hora jugando a los dados da buena cuenta de su compromiso con el proyecto de vanguardia -Espinosa était homme de fidélité- que persigue el anhelo de una nueva interpretación, creativa, de la cultura.

José Jorge Oramas nace el 9 de noviembre de 1911 en la ciudad de Las Palmas de Gran Canaria, en el seno de una familia humilde del Puerto de la Luz. Queda huérfano por la muerte de su madre, fallecida de tuberculosis. Ingresa en la Escuela Luján Pérez en $1929^{1}$, a la edad de dieciocho años, y en ese mismo año exhibe varias obras en la I Exposición colectiva de alumnos. Poco después, en mayo de 1930, una selección de aquella muestra viaja a Santa Cruz de Tenerife para ser exhibida en las salas del Círculo de Bellas Artes, en cuya presentación intervienen los escritores Ernesto Pestana Nóbrega y Pedro García Cabrera, y donde este último lee su conocido ensayo "El hombre en función del paisaje». En 1932 el pintor cae enfermo y es recluido en una habitación del último piso del Hospital San Martín, situado en la parte alta del casco urbano de Vegueta, desde cuya ventana el joven aprendiz de pintor observa las laderas del risco de San Nicolás y traslada al lienzo sus vivos colores. Pinta con unos cuantos pigmentos suministrados por los médicos del hospital. Expone por vez primera de forma individual en 1933 en el Círculo Mercantil de Las Palmas, en donde Agustín Espinosa dicta su subversiva conferencia. El pintor se encontraba gravemente enfermo. Permanece en el hospital hasta 1934, momento en el que empeora y lo trasladan al siquiátrico de Tafira, bajo el cuidado del doctor Rafael O'Shanahan. Muere el 12 de septiembre de 1935, a la edad de veinticuatro años.

Llama nuestra atención la claridad con la que Agustín Espinosa señala la importancia y trascendencia de la pintura, antirretórica y autodidacta, desarrollada por Jorge Oramas desde su humilde cuarto de tuberculoso, con la precariedad de

1 Sobre la Escuela Luján Pérez, véase el ensayo de Pilar Carreño Corbella «La Escuela Luján Pérez en su época dorada», VV. AA. (1992). 
medios y la pobreza que siempre lo acompañó en su corta vida. Sorprende, sí, el acierto de Agustín Espinosa al fijar su mirada crítica sobre aquella pintura primitiva; y sorprende también la militancia con la que elogia la impronta del pintor grancanario, a quien denomina "el gran intuitivo» (Espinosa 1933: 8), y a quien poco después Ramón Feria atribuiría -en su ensayo de interpretación crítica Signos de arte y literatura (1936) - «la más fina objetivación del paisaje insular» (Feria, 1936: 72). El tiempo ha acabado por darles la razón: al cabo de los años, la obra de Jorge Oramas goza, como pocas, de una amplia fortuna crítica en el contexto de la pintura canaria del siglo xx. Su obra continúa despertando, hoy por hoy, múltiples adhesiones. Resulta innegable el alcance y la influencia lograda por la obra de un pintor cuya trayectoria abarca tan solo seis años -desde el ingreso del artista en la Escuela Luján Pérez, en 1929, hasta su temprano fallecimiento, en 1935-, y con una producción escasa compuesta por algo más de medio centenar de lienzos.

La pintura oramasiana ejecuta una lectura insularista de los postulados del arte europeo del momento, que tiene en la neofiguración una de sus vertientes más relevantes. Al igual que en el caso de las corrientes de vanguardia surgidas en España a finales de la década de los años veinte, el conocimiento de las tesis del teórico alemán Franz Roh, quien aborda los problemas de la pintura europea del primer cuarto de siglo, fue determinante para el impulso de renovación que estaba forjándose en la pintura canaria de aquella hora. En efecto, para la Escuela-Taller Luján Pérez, de vocación antiacadémica y autodidacta, y que aplicó el método impresionista de la pintura al aire libre en los paisajes y las medianías insulares, el conocimiento de las ideas de Franz Roh en su ensayo El realismo mágico. Post expresionismo (1925) propició un cambio radical. El libro del teórico alemán -traducido al español en 1927 por Fernando Vela para la Revista de Occidente- adquirió el carácter de auténtico manual para los alumnos de la escuela, pues, tal y como confiesa el artista Felo Monzón, se estudiaban las láminas reproducidas en el libro con mucho detenimiento, hasta el punto de convertirse en una referencia capital para los alumnos más aventajados.

Se ha subrayado muchas veces que el grupo de escritores y artistas de la vanguardia canaria exhibe una actitud que celebra, con total adhesión y complicidad, sin ambages, cualquier manifestación de lo nuevo, participando de la expresión de un deseo compartido de reinvención de la cultura y del paisaje, y dando sentido a las islas en tanto que lugar desde el que se ejerce esa reflexión. Existe, por lo tanto, un proyecto plural que persigue reconocer los signos propios del espacio geográfico y de la cultura desde donde Canarias se incorporara a la modernidad europea. Es, en este contexto, y no otro -en este enclave de signo epifánico-, donde hay que situar al Agustín Espinosa de Media hora jugando a los dados y su acercamiento a la obra de Jorge Oramas: la pintura del alumno de la Escuela Luján Pérez ejemplifica el encuentro entre los signos propios de la insularidad y la puesta en práctica de la lección moderna denominada nueva figuración o nueva objetividad. Y es que la de Jorge Oramas se inscribe en la tradición de la mejor pintura metafísica europea, cuya fuente de inspiración no es otra que la realidad sencilla, humilde y pobre de los objetos cotidianos y paisajes circundantes: unas piteras, unas rocas en el camino, unas casas canarias. Sus paisajes, naturalezas muertas y retratos se muestran, aquí, here- 
deros del postexpresionismo de entreguerras; esto es, hijos del realismo, de aquella mágica racionalidad que alentaba a los pintores europeos de la denominada rappel à l'ordre. Hay en su obra una preferencia por las formas clásicas y por un mundo ordenado que, en su caso, encuentra pleno sentido en el tratamiento de la luz y del color.

Los protagonistas del capítulo de excepción que cristaliza en la vanguardia canaria exploran un camino que deja atrás los discursos del regionalismo al uso y del tipismo pintoresco de provincias, en un intento de abrirse hacia una construcción cultural forjada desde las Islas. La comprensión de este compromiso -la asimilación de lo propio y el salto hacia lo moderno- implica un ejercicio de autoconciencia que se fragua a partir de lo que el mismo Agustín Espinosa denomina «la generación literaria que amanece en Canarias con La Rosa de los Vientos» ${ }^{2}$, revista de vanguardia cuya primera entrega aparecía en abril de 1927 de la mano del mismo Agustín Espinosa, Ernesto Pestana Nóbrega y Juan Manuel Trujillo. Con el inicio de La Rosa de los Vientos venía a cristalizar el primer gran proyecto, con objetivos conscientes y precisos, de la vanguardia canaria. Acompañaron a los escritores de La rosa en aquella hazaña otro grupo de jóvenes escritores -Eduardo Westerdahl y Domingo Pérez Minik; Pedro García Cabrera y Emeterio Gutiérrez Albelo- que desde las páginas literarias del diario tinerfeño La Prensa, al igual que desde la revista miscelánea Hespérides -cuya primera entrega se remonta a 1925-, contribuyen al debate sobre la consecución de un espacio propio de creación. Las tesis de unos y de otros confluirían pronto dentro de los márgenes, convergentes, que planteó la revista internacional de cultura Gaceta de Arte (1932-1936). No es lugar, aquí, para extendernos sobre la historia de aquella aventura, pues se ha abordado ya en otras muchas ocasiones, desde que el profesor José Miguel Pérez Corrales publicara su Cuaderno de Bitácora de la Vanguardia Insular, en seis entregas ofrecidas entre julio y octubre de 1981 en las páginas de Jornada Literaria, suplemento cultural del diario La Jornada Deportiva de Santa Cruz de Tenerife 3 .

En esa corriente de desapego vanguardista hacia las manifestaciones del tipismo más rancio y del costumbrismo; esto es, hacia las formas regionales adulteradas de las que hablaría Pedro García Cabrera en sus escritos, hay que entender la reivindicación del joven pintor grancanario que realiza Agustín Espinosa en su conferencia dictada en beneficio de la pintura oramasiana. Pero también en la defensa y apuesta por cierto espíritu autodidacta de aprendizaje, en contraposición a la tradicional rutina académica, una de las premisas centrales propugnadas por la

${ }^{2}$ La cita de Espinosa es conocida. Puede consultarse en su texto «Poesía atlántica. EGA: CDLP. 1930", Heraldo de Madrid, 2 de abril de 1931. También puede consultarse en Espinosa 1980.

${ }^{3}$ Este trabajo sirvió de guía para trazar la trayectoria de la vanguardia en Canarias entre 1926 y 1936, partiendo, como el mismo autor explica, de un material casi desconocido hasta la fecha, y ha servido de impulso para otras muchas publicaciones que han aparecido entre ese mismo año $y$, prácticamente, el día de hoy. Pueden consultarse las entregas 31, 34, 36, 38, 44, y 46 de dicho suplemento, aparecidas los días 4 y 25 de julio, 8 y 22 de agosto, 3 y 17 de octubre de 1981. Véase también Entre islas anda el juego (Nueva literatura y surrealismo en Canarias, 1927-1926), en la Colección Edad de Oro, dirigida por Emmanuel Guigon y Ana Isabel Herce para el Museo de Teruel, Teruel, 1999. 


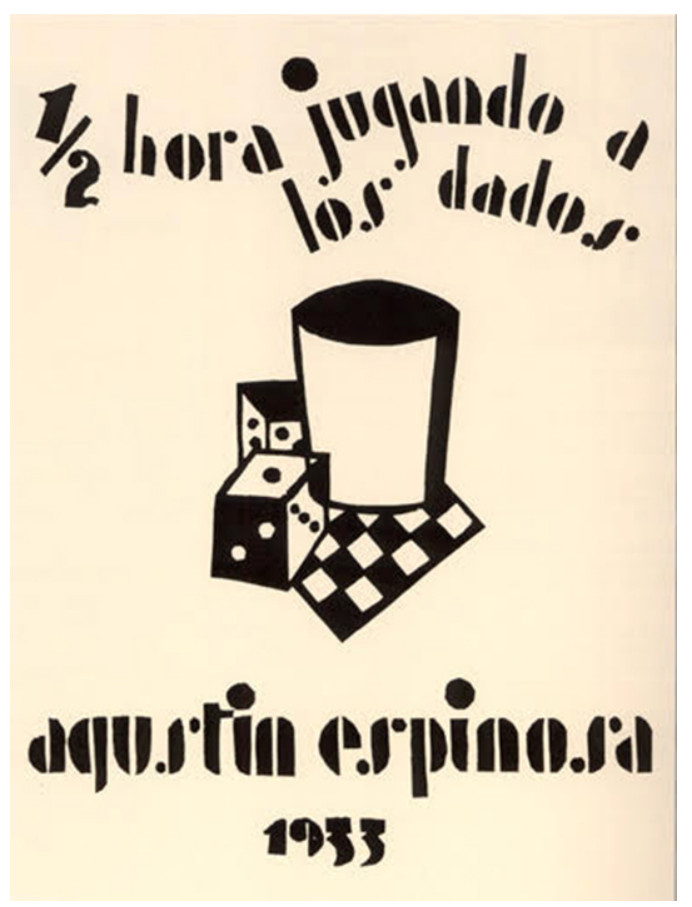

Cubierta de Media hora jugando a los dados (1933).

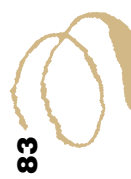

Escuela Luján Pérez y puestas en práctica entre sus alumnos. De ahí, tal vez, que el autor dedique Media hora jugando a los dados a Fray Lesco -seudónimo del escritor Domingo Doreste, director de la Escuela desde 1918-, que cuenta para el proyecto docente con las lecciones impartidas por el arquitecto Enrique García Cañas y por los pintores Nicolás Massieu y Juan Carló. Se entiende, así, que Agustín Espinosa ponga en práctica el libre juego de una escritura desasida totalmente de cualquier amarre, y siga una estrategia lúdica similar a la hora de abordar su texto de celebración de la obra del pintor. Lejos, muy lejos, ha quedado la recensión convencional al uso y el estilo académico.

Para todos, he comprado yo una caja de dados. He comprado, también, para todos, un cubilete, donde se geste cada sorpresa y madure. Vamos a jugar esta tarde un rato a los dados. Perdonad, señoras y señores, que sea yo solo el cubiletero y vosotros los que ganéis o perdáis (Espinosa 1933: 12).

El texto de la conferencia sería publicado por su autor en el mes de julio de 1933, con un dibujo en la cubierta realizado por Felo Mozón: un cubilete y un par de dados sobre un tablero de damas, a la manera de acompańamiento al nombre del autor y al título del cuaderno. Nos encontramos ante una escritura que no señala, 
sino que sugiere; esto es, que no analiza, determina y concluye, sino que dialoga y permanece próxima al alcance de la pintura que comenta. Una escritura antirrealista, que es más una prolongación y una amplificación del objeto reseñado que una disertación crítica. Una predisposición del lenguaje que amplifica lúdicamente aquello que es comentado y celebrado, y que viene a corroborar la afirmación de José Miguel Pérez Corrales cuando señala que en Agustín Espinosa apreciamos un constante fetichismo hacia lo nuevo. En efecto, su lenguaje parece celebrar cada cosa que nombra mientras da rienda suelta al impulso espontáneo de la imagen poética. Es en este mismo sentido en el que Fernando Castro Borrego afirma que Media hora jugando a los dados "constituye un ejemplo de comunión poética más que un ejercicio ortodoxo de crítica de artenuevo» (Castro Borrego 1983: 62). Por supuesto, esta espontaneidad creadora, este instinto de juego lingüístico, no es una forma de comentario exclusiva de Espinosa, sino practicada por varios miembros del grupo de vanguardia, entre ellos, por Emeterio Gutiérrez Albelo, quien, no en vano, reseña para la prensa local varios de los textos publicados por sus compańeros de viaje en un mismo sentimiento de correspondencia y compromiso generacional.

El escritor Agustín Espinosa es uno de los que mejor escriben en España. Pocos como él conocen tan sabiamente su oficio; pocos, muy pocos, confeccionan tan limpias planas, tales caligráficos primores. Tiene -y de ahí la clave- un sombrero de profunda copa, de amplísimas alas, en donde deposita miles y miles de papeles con las más vividas y colgantes palabras. Agustín, con sus manos diminutas, delgadas, ágiles -manos de prestidigitador-saca (no dadaísticamente, no al azar; sino con lucidez, con deliberación y vigencia) los términos más precisos. La exactitud es su norma. La claridad, su original impulso ${ }^{4}$ (Gutiérrez Albelo 1935: 7).

Conviene señalar, a propósito de la escritura libre de Agustín Espinosa -en palabras del mismo Gutiérrez Albelo, el barman insuperable de cocktails novísimos-, que esta se inscribe dentro de lo que se ha llamado poética veintisietista o del arte nuevo, donde existe un continuo diálogo entre poesía y pintura. Se trata de una denominación que, lejos de reducirse estrictamente a un grupo de escritores concretos vinculados a la Generación del 27 , sus premisas se expanden y se manifiestan a través de propuestas literarias y artísticas de espíritu habitualmente subversivo, ajenas a sentimentalismos e inmersas en un proceso de deshumanización artística. Así, como también sucede en el resto de España, los escritores de vanguardia trascienden con facilidad los estrechos márgenes de los géneros literarios, probablemente por causa de esa empatía generacional que contagió por igual a todos los lenguajes artísticos nuevos. Como en el caso de la escritura de Agustín Espinosa y Media hora jugando a los dados, parece imposible determinar dónde empieza el texto de presentación y dónde el poema; dónde el relato y dónde el género dramático. Más bien, el autor establece su propio género, acaso determinado por rasgos de estilo propios. En estos términos de convergencia o de porosidad interartística se expresa el crítico Eugenio

4 También recogido en Poemas surrealistas y otros textos dispersos (1929-1936), 1988. 
Carmona cuando aborda la naturaleza de la denominada pintura del 27 como uno de los momentos cruciales del encuentro entre poetas y pintores. Carmona subraya el hecho de que, si bien el término que alude a esa generación solo servía, en un principio, como referencia para un determinado grupo de escritores, pronto se produce una amplificación del alcance del término Generación del 27, que pasa «de epígrafe compilador de grupo de creadores de tendencias estéticas más o menos cómplices o compartidas al espectro comprensivo de todo un espacio cultural español». Y subraya que, desde su origen, el concepto Generación del 27 se expande en forma de círculos concéntricos, y al citarlo se alude a un espacio o universo de creación común a muchas disciplinas diversas, como el ensayo, la narrativa, el teatro, el pensamiento, el periodismo, el cine, la música o la fotografía. «Decir que un determinado creador pertenecía a la Generación del 27 era decir que situó el primer espacio maduro y perdurable de su obra entre mediados de la década de 1920 y 1936», subraya, entendiendo que la producción cultural quedaba determinada por «un cierto número de claves o invariantes alusivas prácticamente todas al modo en que quedaba afrontado el encuentro con la modernidad madura [...]» (Carmona 2005: 10). En este ambiente estimulante de los años veinte y treinta, de espíritu optimista y deportivo, que reinventa a través de la creación lingüística o plástica el espacio cultural que le es propio, surgen obras excepcionales como lo son la pintura de José Jorge Oramas y, paralelamente a ella, Media hora jugando a los dados.

El texto de Agustín Espinosa es concebido como una obra independiente, poética y autónoma en sí misma. En cierto sentido, su lectura vuelve a retrotraernos a las palabras de Paul Dermée escogidas para abrir las páginas de Lancelot, $28^{\circ}-7^{\circ}$, su Guía integral de una isla atlántica. Recordemos que en el primer número de la revista creacionista Nord-Sud, el poeta analiza la que él considera necesaria autonomía de la obra de arte basándose en un inusual parangón: «Crear una obra que viva fuera de sí, de su propia vida, y que esté situada en un cielo especial, como una isla en el horizonte» (Espinosa 1929: 5). La obra de arte, comparada así con la isla -al igual que una pintura de Jorge Oramas-, ha de caracterizarse por la autonomía, el desasimiento, la diferencia y la concentración; ha de confundirse con un espacio arquetípico y revelarse como un microcosmos.

Agustín Espinosa divide el texto de su conferencia en secciones que abren una ventana al carácter enigmático de una pintura que, aun considerando el corto espacio de tiempo con el que contó, no ha dejado de sorprendernos por la fascinante intensidad de sus misteriosas imágenes y su luminosidad de inquietante sosiego. Las sucesivas secciones en que se estructura el discurso de Agustín Espinosa fueron concebidas como si de un texto poético se tratara. Varios fragmentos lo estructuran de forma casi simétrica: una presentación y dos fragmentos iniciales - «La risa del mundo" y «Odio, amistad y un cofre encantado»-; cuatro secciones centrales - «La fiesta del alcohol», «La fiesta de la sangre», «La fiesta del hambre», «La fiesta de la crudeza»-. Y, finalmente, otras tres secciones de cierre: «Anunciación», «Pintar y hacer cuadros» y «La vida es sueño y el cubiletero imprudente». Según la crónica aportada por el artista Felo Monzón, compañero de Oramas en la Escuela Luján Pérez, el pintor, aunque se encontraba enfermo, pudo asistir a la presentación y escuchar las palabras surrealistas de Agustín Espinosa. Según su relato, el pintor «la 
aceptó, pero sin expresar una opinión clara sobre ella, quizá por falta de seguridad, pero de lo que sí estoy seguro es que captó la importancia que le estaba dando a su obra, por ese estado de pureza esencial que le envolvía» (Jiménez Doreste 1987: 18). El lenguaje empleado por el escritor grancanario insiste en su componente trágico y, si es verdad que existen equivalencias y vasos comunicantes con Crimen (1934), también lo es que se alimenta de la inventiva desplegada en Lancelot, $28^{\circ}-27^{\circ}$. De hecho, la conferencia de Agustín Espinosa retoma una de las imágenes diseminadas en la obra creacionista de 1929, en uno de cuyos capítulos el protagonista alegórico, Lancelot, juega a inventar la fundación de los municipios de Nazaret y Mozaga lanzando los dados de su cubilete sobre el tablero de la isla de Lanzarote y creando, de este modo, las casas blancas de la arquitectura tradicional sobre la tierra volcánica. Por estas y otras alusiones, como Le cornet à dés (1913), de Max Jacob, o la pintura cubista de Juan Gris y de Picasso, José Miguel Pérez Corrales descarta la total filiación surrealista del texto, puesto que «podemos decir que si Crimen mira hacia lo interior y Lancelot hacia lo exterior, Media hora jugando a los dados funde mirada subjetiva y mirada objetiva, y de ahí su peculiar situación entre dos luces» (Pérez Corrales 1986: 554). Con todo, el crítico subraya, en la reedición de los textos de Espinosa preparada para las ediciones de Insoladas en 2018, que "Media hora jugando a lo dados es -y creo que lo será hasta el fin de los tiempos- la conferencia más extraordinaria que se ha dado nunca en Canarias" (Espinosa 2018: 285).

En la introducción al texto el escritor explica la génesis de su conferencia y da cuenta del objetivo y la razón de la urgencia de su escritura: la necesidad de llamar la atención sobre el caso de Jorge Oramas, el infortunio de su vida y el alcance de su obra.

El caso de José Jorge Oramas era -y lo sigue siendo aún- un caso desnudo. Apremiaba una solución. Había que meter el hombro por él como quiera que fuese. Por humanidad. Por insularismo. Por fervor de hombres que vivimos cara a un mar que todo lo engulle y devora como los boicoteadores pájaros de la inventiva de Aristófanes. Había que salvar a un ágil muchacho a quien la vida se le revolvía de pronto haciendo su presa en lo que tenía ya empuje de garra. Era deber de ciudadanía proteger su sombra en el instante de la emboscada, gritarle: iieh!!, antes de que fuera demasiado tarde. Y parecía que todos nos habíamos puesto de acuerdo para pactar con el fantasma de la pesadilla, para abrazarnos en unanimidad canallesca, pueril, obtusa e irrisoria (Espinosa 1933, p. 6).

Llama la atención hasta qué punto Agustín Espinosa utiliza Media hora jugando a los dados para arremeter contra lo que el escritor considera pasividad y desidia de los habitantes de las islas para con su cultura, pues a todos hace partícipes de la trágica «orfandad» del pintor. El escritor nos habla de «una orfandad de la que toda Gran Canaria es responsable» (Espinosa 1933, p. 7) de modo que la figura del pintor cobra, aquí, una dimensión simbólica. Se trata de una «orfandad a la que todos le hemos arrojado, tú, oficinista, tú, bohemio, tú proletario, tú, escritor, tú, artista, tú político, tú, canario joven, maduro o viejo, tú, que sueñas para tu isla una suerte más ancha, que mezclas con tu fortuna la fortuna de ella» (Espinosa 1933, p. 7). El escritor parece anunciar la conocida sentencia que poco después expresaría Juan 
Manuel Trujillo al sugerir que Canarias se ignora e ignora que se ignora, denunciando la laxitud de los habitantes de las Islas en la defensa de los signos de su propia cultura, y reclamando, de este modo, la necesidad de participar en la construcción de una tradición propia. Es, tal y como subraya Juan Manuel Bonet, un auténtico «alegato» o una "violenta diatriba»; es decir, un discurso que persigue denunciar y señalar de forma explícita y sin tapujos «la incapacidad del público y de las instituciones canarias para acoger lo nuevo, para acoger las voces verdaderamente originales» (Bonet 1992: 60).

Y es que Agustín Espinosa comprende la importancia de los logros de la pintura oramasiana; esto es, la síntesis que opera en aquella obra; la conjunción entre los valores de la neofiguración europea y la condición insular, manifestada en los signos de la naturaleza seca, sin colores, de las medianías insulares. El ensamblaje y el encuentro entre lo moderno y lo vernáculo que, al fin, se manifiesta de forma clara en la materialidad pictórica. En efecto, si bien los paisajes que Jorge Oramas traslada al pincel se alimentan del lugar y del tiempo que le tocara vivir, en su mirada llegan a convertirse en lo que el escritor Andrés Sánchez Robayna contempla como escenas esenciales; es decir, imágenes arquetípicas del paisaje insular reconocibles dentro del imaginario cultural y colectivo. La pintura de José Jorge Oramas -el pintor niño, el autodidacta, el aprendiz de barbero, el alumno de la Escuela Luján- traspasa el ámbito de su secreta orfandad para devenir pintura que nos concierne en tanto que sociedad y nos habla desde su eterno presente continuo. Así pues, en virtud de esa aspiración constructiva y de su calidad iluminante Jorge Oramas crea un imaginario pictórico que parece conducirnos hacia lo que el crítico llama «el ámbito de las imágenes primitivas e inconscientes» (Sánchez Robayna 2018: 23) mismo sentido en el que, en sus ensayos de interpretación de un nuevo regionalismo, Pedro García Cabrera reivindicaba la necesidad de recuperar la esencia, las protoformas primitivas de los elementos de la naturaleza insular como elementos desde los que construir una cultura moderna.

Así, por ejemplo, en Barrio de San Nicolás, en Aguadoras -quizás uno de los cuadros más reproducidos, perteneciente a las colecciones del CAAM de Las Palmas de Gran Canaria-, o en Rocas y pitas, el pintor lleva al lienzo algunas de sus composiciones más representativas desde un punto de vista iconográfico. En esta última, el elemental agave, semioculto tras el enjambre de formas pétreas, y la obertura del camino bajo la sombra que proyectan las rocas, invita a traspasar el umbral de la realidad inmediata. El pintor ejecuta el dibujo de las formas marcándolas con una fuerte geometrización que, de alguna manera, viene a privilegiar la pintura frente a la realidad que se interpreta. La naturaleza es aquí reinventada en el espacio pictórico. El contraste entre la luz cenital de los espacios abiertos de las medianías insu-

5 Véase Jorge Oramas o El tiempo suspendido, un largo ensayo de reciente publicación dedicado al pintor José Jorge Oramas (1911-1935). Un pintor breve; o no tan breve, como viene a demostrar el ensayista a lo largo de los veintitrés capítulos que van desgranando, paso a paso, distintos aspectos de la obra del pintor grancanario. 


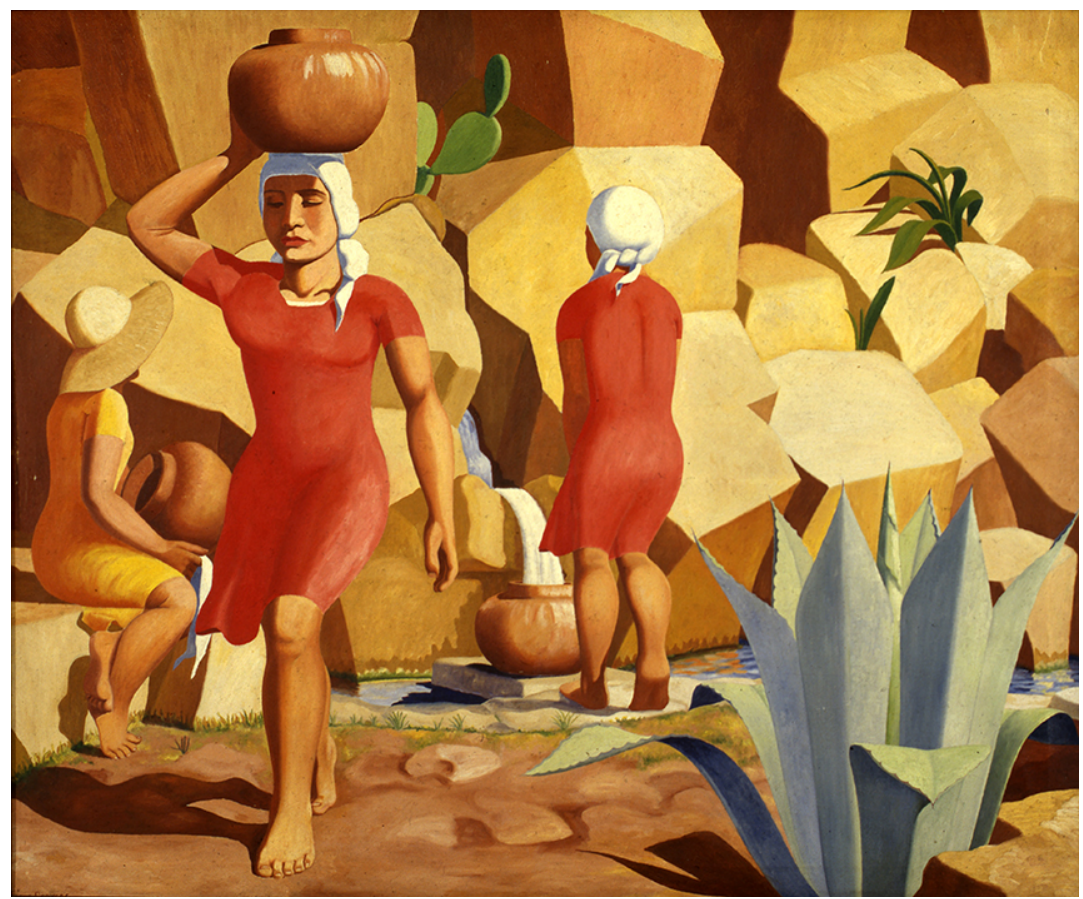

Aguadoras (ca. 1932-1935).

Óleo sobre lienzo, $110 \times 132 \mathrm{~cm}$. Colección CAAM.

lares y las sombras que se proyectan -y que abren en el lienzo un pozo de nocturna y turbadora profundidad- provoca una imagen espectral, una imagen visionaria y metafísica de lo real. La pintura oramasiana practica un acentuado esquematismo, y en ella se recogen signos elementales de la naturaleza atlántica: formas ascensionales, verticales, como ocurre en esta composición de rocas y pitas, riscos y montañas, y en las que asistimos a un singular uso del lenguaje pictórico moderno que tanto nos recuerda a las cuentas y reflexiones de un joven Andrés de Lorenzo-Cáceres - protagonista, al igual que Espinosa y que el propio pintor, de la generación de la vanguardia canaria- al referirse al "paisaje espiritualizado» y «verticalmente lírico» (Lorezo-Cáceres 1990: 44), como uno de los signos característicos de la pintura -y de la poesía- de los creadores insulares de principios de los años veinte y treinta del pasado siglo ${ }^{6}$.

${ }^{6}$ Para una comprensión de la estética poética y artística de la vanguardia canaria siempre hemos considerado imprescindible el volumen Isla de promisión, publicado en 1990 por el Instituto de Estudios Canarios en edición de Miguel Martinón. 


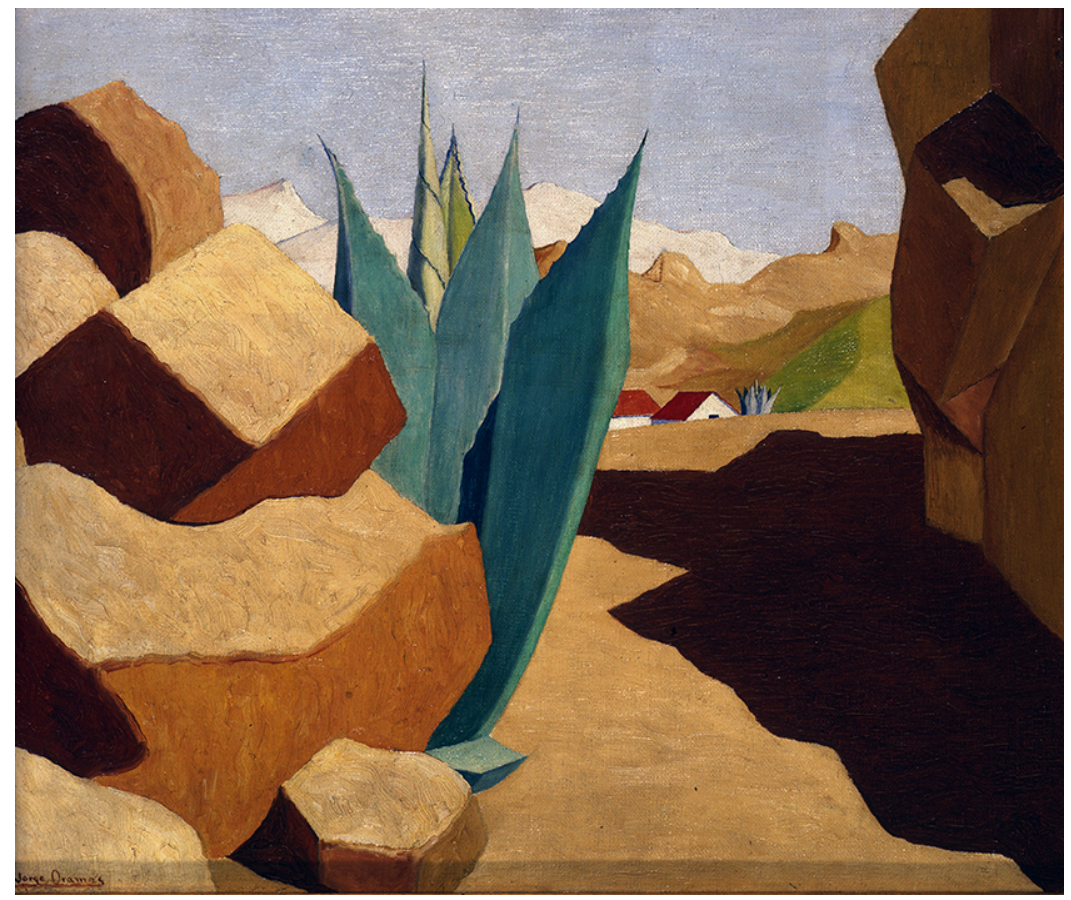

Rocas y pitas (ca. 1932-1935).

Óleo sobre lienzo, $36 \times 42 \mathrm{~cm}$. Colección CAAM.

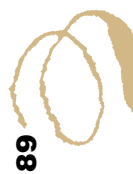

Con todo, si es cierto que la obra de Jorge Oramas forma parte de un modo peculiar de ver y de entender el mundo, dotando a la pintura de una sobreiluminación cromática sin precedentes, tal vez sea el óleo sobre lienzo Dos figuras la pieza que ejemplifica mejor esa tendencia hacia lo enigmático de la existencia. Hay, en esta obra, una preferencia por los volúmenes plenos y rotundos; esto es, por una solidez escultórica en la formas. El paisaje se pierde en lontananza por un camino de lomas y casas cúbicas, de pitas y chumberas. La luz y el color desbordante lo inunda todo. $Y$ en el centro de este escenario eminentemente rural, mediante el impulso clásico de la nueva figuración, se erigen las dos protagonistas del lienzo, enormes, cual seres inanimados. ¿Una imagen que se proyecta en un espejo?, ¿el desdoblamiento de una única experiencia?

Agustín Espinosa llega muy lejos en su lectura de la obra del pintor grancanario, al sostener que «Oramas tiene como nadie ha tenido en Canarias el sentido de la luz y del color de nuestra naturaleza atlántica» (Espinosa 1933: 8). Una pintura que, en palabras de Espinosa, obedece tanto al instinto primario del autor como a su carácter mágico: «Tiene rellenas de colores de paisajes de su isla las manos. Tiene en cada dedo cien insularios paisajes que se le asoman a las yemas, afanosos de expresarse en plástica ternura, peregrinos de óleos quiméricos, de espectrales pinceles, 


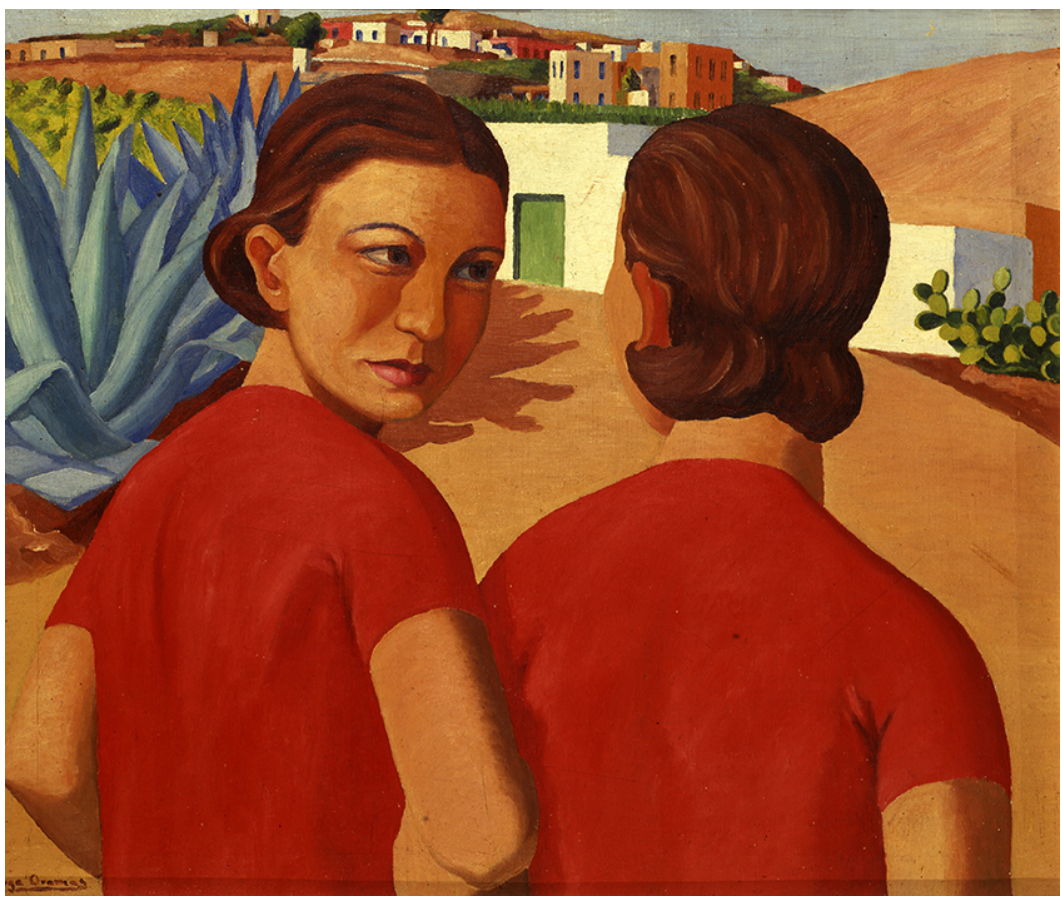

Dos campesinas o Dos figuras (ca. 1932-1935).

Óleo sobre lienzo, $36 \times 42 \mathrm{~cm}$. Colección CAAM.

de utópicas telas [...]» (Espinosa 1933: 18). Con todo, el texto le sirve a Espinosa de pretexto para realizar una creación totalmente libre que, por momentos, supera la obra referenciada y adquiere visos de escritura surreal que avanza en un sentido distinto al de aquella pintura, pues hay en su escritura «una presencia de lo gestual, de lo automático, que no está en la obra de Oramas, que es una obra medida, contenida, en la que la geometría cumple un papel siempre importante» (Bonet 1992: 70). Media hora jugando a los dados inaugura el comentario de interpretación de la obra oramasiana; esto es, la tradición de exégesis interpretativas de una pintura que no ha dejado de depararnos, hasta nuestros días, diversas aproximaciones y monografías, las últimas de muy reciente aparición, como lo son Jorge Oramas o El tiempo suspendido, publicado en 2018 por Andrés Sánchez Robayna para Galaxia Gutenberg; o el ensayo del también poeta Fernando Gómez Aguilera, Inocencia y herida: Jorge Oramas, que ha aparecido en 2020 en la editorial madrileña Mercurio. Conviene subrayar, por tanto, el hecho de que la obra de José Jorge Oramas ocupa, hoy por hoy, un lugar de excepción en la historia de la pintura española de vanguardia del siglo $\mathrm{xx}$, incluso a pesar de su tibia presencia en las grandes colecciones públicas de arte en Espańa. Conviene recordar, en este sentido, las exposiciones producidas por el Museo Nacional Centro de Arte Reina Sofía (MNCARS) y el Centro Atlántico de 
Arte Moderno (CAAM) en 2003, bajo el comisariado de Juan Manuel Bonet y con el significativo título de José Jorge Oramas, metafísico solar. A todo ello se suman así los trabajos aportados por Josefa Alicia Jiménez Doreste o los escritos sobre pintura canaria de Fernando Castro, quien denomina a José Jorge Oramas, refiriéndose a la pureza de su estilo, el más raro de los pintores que las Islas han dado. Por supuesto, a estos esfuerzos de interpretación de la obra de este pintor esencial en la tradición de la pintura canaria debemos añadir otras propuestas de contextualización, entre las que destacan las aportaciones siempre lúcidas del crítico de arte y literatura Nilo Palenzuela, o la contribución del también crítico y comisario Orlando Franco, quien en 2008 comisarió la exposición Irradiaciones de Oramas.

RECIBIDO: octubre de 2020; ACEPTADO: noviembre de 2020 


\section{BIBLIOGRAFÍA}

Bonet, Juan Manuel (1992): «Oramas, pintor esencial», en Andrés Sánchez Robayna (ed.), Canarias: las vanguardias históricas, Las Palmas de Gran Canaria: CAAM-Viceconsejería de Cultura y Deportes del Gobierno de Canarias.

Bonet, Juan Manuel (2003): José Jorge Oramas, metafísico solar, Madrid / Las Palmas de Gran Canaria: MNCARS / CAAM.

Carmona, Eugenio (2005): «Las poéticas del arte nuevo y los círculos concéntricos de la Generación del 27. 1926-1931», en Juan Pérez de Ayala y Guillermo de Osma (eds.), La pintura del 27, Madrid: Galería Guillermo de Osma.

Castro Borrego, Fernando (1983): «Modernistas brasileños y vanguardistas canarios: historia comparada de un fervor», Syntaxis, núm. 2, Santa Cruz de Tenerife.

Delgado, Félix (1933): «Media hora jugando a los dados», Revista Azor, 15 de julio, n. ${ }^{\circ}$ x.

Espinosa, Agustín (1929): Lancelot, $28^{\circ}-7^{\circ}$. Guia integral de una isla atlántica, Madrid: ALFA.

Espinosa, Agustín (1931): «Poesía atlántica. EGA: CDLP. 1930», Heraldo de Madrid, 2 de abril.

Espinosa, Agustín (1933): Media hora jugando a los dados, Las Palmas de Gran Canaria.

Espinosa, Agustín (1980): Textos (1927-1936), edición de Alfonso de Armas Ayala y Miguel Pérez Corrales, Santa Cruz de Tenerife: Aula de Cultura.

Espinosa, Agustín (1987): Media hora jugando a los dados, 1933, Las Palmas de Gran Canaria [edición facsímil], Gobierno de Canarias.

Espinosa, Agustín (1999): Crimen. Media hora jugando a los dados [Eugenio Padorno ed.], Zaragoza: Libros del Innombrable.

Espinosa, Agustín, (2018): Media hora jugando a los dados. Textos 1932-1933 [José Miguel Pérez Corrales ed.], Santa Cruz de Tenerife: Insoladas.

Feria, Ramón (1936): Signos de arte y literatura, Madrid: El Discreto.

Franco, Orlando (2008): Irradiaciones de Oramas, Las Palmas de Gran Canaria: La Caja de Canarias.

Gómez Aguilera, Fernando (2020): Inocencia y herida: Jorge Oramas, Madrid: Editorial Mercurio.

Gutiérrez Albelo, Emeterio (1933): «Tres dados de Agustín Espinosa», La Tarde, Santa Cruz de Tenerife, 21 de agosto.

Gutiérrez Albelo, Emeterio (1935): «Agustín Espinosa», La Tarde, 2 de abril.

Gutiérrez Albelo, Emeterio (1988): Poemas surrealistas y otros textos dispersos (1929-1936), recopilación e introducción de Andrés Sánchez Robayna, La Laguna: Instituto de Estudios Canarios.

Jiménez Doreste, Josefa Alicia (1987): El pintor José Jorge Oramas (1911-1935), Santa Cruz de Tenerife: CajaCanarias.

Jiménez Doreste, Josefa Alicia (1991): José Jorge Oramas, Islas Canarias: Biblioteca de Artistas Canarios, Gobierno de Canarias.

Lorenzo-Cáceres, Andrés de (1990): Isla de promisión, edición, introducción y notas de Miguel Martinón, La Laguna: Instituto de Estudios Canarios.

Palenzuela, Nilo (2007): Moradas del intérprete, México: Fondo de Cultura Económica.

Pérez Corrales, José Miguel (1986): Agustín espinosa, entre el mito y el sueño, tomo II, Las Palmas de Gran Canaria: Cabildo Insular de Gran Canaria. 
Pérez Corrales, José Miguel (1981): «Cuaderno de bitácora de la vanguardia insular I. 1926-1927», Jornada Literaria, Santa Cruz de Tenerife, 4 de julio.

Pérez Corrales, José Miguel (1999): Entre islas anda el juego (Nueva literatura y surrealismo en Canarias, 1927-1926), Teruel: Colección Edad de Oro, Museo de Teruel.

RoH, Franz (1927): Realismo mágico. Postexpresionismo, Madrid: Revista de Occidente.

SÁnchez Robayna, Andrés (1980): «Signos de Jorge Oramas», El Día, Santa Cruz de Tenerife, 5 de diciembre.

Sánchez Robayna, Andrés (1988): Poemas surrealistas y otros textos dispersos (1929-1936), La Laguna: Instituto de Estudios Canarios.

Sánchez Robayna, Andrés (2018): Jorge Oramas o El tiempo suspendido, Barcelona: Galaxia Gutenberg.

VV.AA. (1992): Canarias: las vanguardias históricas, Andrés Sánchez Robayna (ed.), Las Palmas de Gran Canaria: CAAM-Viceconsejería de Cultura y Deportes del Gobierno de Canarias.

VV.AA. (1997): Franz Roh y la pintura europea (1917-1936), Valencia: Instituto Valenciano de Arte Moderno, IVAM.

VV.AA. (2003): La Rosa de los Vientos (1927-1928), edición facsímil de Alejandro Krawietz, con un estudio crítico de Carlos Brito Díaz, Santa Cruz de Tenerife: CajaCanarias.

VV.AA. (2005): 70 aniversario de la muerte de José Jorge Oramas (1911-1935), Boletín de la CasaMuseo Gutiérrez Albelo, Francisco León (ed.), Icod de los Vinos, Can Mayor, n. ${ }^{\circ}$ XIv.

Westerdahl, Eduardo (1933): «Agustín Espinosa. Media hora jugando a los dados», Gaceta de Arte, n. ${ }^{\circ}$ XviII, Santa Cruz de Tenerife. 
